\title{
El maíz, fuente de cultura mesoamericana
}

Corn as a source of mesoamerican culture

DOI: https://doi.org/10.5377/koot.v0i11.10737

URI: http://hdl.handle.net/11298/1193

\author{
Dr. Ramón D. Rivas \\ Antropólogo Social y Cultural \\ Director de Cultura \\ Universidad Tecnológica de El Salvador \\ ramon.rivas@utec.edu.sv \\ ORCID: https://orcid.org/0000-0003-0933-9935 \\ Fecha de aceptación: diciembre 2020
}

\section{Resumen}

Historia, religión, cultura y utilidad del maíz (Zea mays) se juntan en este artículo, que solo persigue dar una muestra somera sobre la importancia y utilidad de esta prodigiosa planta milenaria que su fruto ha sido fuente principal de alimentación en Mesoamérica.

Palabras clave: Maíz - Aspectos culturales - Historia - Mesoamérica. Maíz - Aspectos sociales - Mesoamérica. Maíz - cultivo - Mesoamérica. Maíz aspectos socioeconómicos - Mesoamérica.

\section{Resumen}

This article compiles the history, religion, culture and usage of corn with the sole purpose of providing a small sample on the utility and importance of such prodigious millenary plant which fruit has been the main food source in Mesoamerica.

Key words: Corn - Cultural aspects - History - Mesoamerica. Corn - Social aspects - Mesoamerica. Corn - Cultivation - Mesoamerica. Corn - Socioeconomic aspects - Mesoamerica. 


\section{Introducción}

El maíz, no solo es uno de los alimentos y cultivos más antiguos, sino, históricamente, la base de la supervivencia para los habitantes de la región mesoamericana. Se cree que este grano es propio de nuestra región. Fue pasando por el territorio americano y llegó a El Salvador para convertirse en un cultivo permanente, que ofrece una base de alimentación muy importante. Cronistas del siglo XVII se refieren a la tortilla con chile o sal, como la dieta básica de la mayoría de habitantes del actual El Salvador.

La extensión del cultivo y consumo del maíz es una práctica común de los pueblos prehispánicos, desde México hasta Panamá, así como de otros granos como el frijol, maicillo y verduras; también se incluye el ayote, chile y el cacao, los cuales pueden considerarse como alimentos básicos extendidos por toda Mesoamérica: desde México hasta Nicoya, en Costa Rica.

Según datos arqueológicos, el maíz fue otra especie americana que se difundió a China, posiblemente por la presencia portuguesa en Macao, en el siglo XVI. La domesticación del grano fue un proceso paulatino, que pudo transformar al ancestral teosintle, el cual, según algunos investigadores, muchas de las valiosas propiedades del maíz híbrido, se deben a la hibridación introgresiva del teosintle, nombre que en nahuaü (lengua azteca) significa «sostén de los buenos».

Con respecto al lugar probablemente del descubrimiento del maíz, de acuerdo a Román Piña Chan, citando a Chinchilla Aguilar (1974): "En la actualidad las evidencias existentes se inclinan a favor de la región mexicana-centroamericana; pudiendo ser el área de Chiapas-Guatemala el centro de origen de las razas afectadas por la introgresión del teocintle". Es importante señalar que la teosintle es una hierba silvestre que se cultivaba en México; y de ella se da origen al maíz, que por mucho tiempo se dudó que estas dos especies podían estar relacionadas. El cultivo de este alimento básico aún en la actualidad, habría iniciado hace 10.000 o 7.000 años. Existen teorías sobre el origen de este cultivo.

Por ejemplo, en 1953 Silvia Rendón lanzó una tesis en la cual sostenía que había evidencia testimonial histórica y lingüística de que el maíz no era originario de América, sino de la cuenca del Danubio o de Transcaucasia.

Esta teoría fue apoyada en 1959 por el botánico Croizat, quien "aportó algunas pruebas botánicas y antropológicas en favor de la hipótesis de que el maíz se originó en Asia. Salvando estos casos exóticos, los científicos son unánimes en reconocer a América como el continente 
donde se originó, ya que no se ha encontrado una sola mazorca en el Viejo Mundo anterior a 1492, lo que contrasta con las 25.000 halladas desde Arizona hasta Guatemala antes de dicha fecha" (Mundorojas, 2009).

Lógicamente no entraremos a reflexionar sobre el origen del maíz a fondo, ya que aún no hay datos en firme que nos permitan analizar su evolución en el mundo. Lo que si podemos hacer es comentar reflexionar es sobre cómo este producto llegó a toda la región de América y acerca de los diferentes usos que los pueblos le han dado en el transcurso de los tiempos. En el libro Hijos del Maiz, publicado por la Red por una América Latina libre de transgénicos, se afirma que

el maíz es la planta cultivada con los más profundos procesos de domesticación que existe, pues es el resultado de un proceso que llevó entre 500 y 2000 años, hasta que sus creadores consiguieron obtener una planta con los rasgos propios de una especie cultivada. Fueron las mujeres quienes, luego de un continuo proceso de experiencias acumuladas sobre el uso y transformación de las plantas útiles, de aprender dónde encontrarlas y de experimentar cómo guardarlas, que iniciaron los procesos de domesticación del maíz.

Como es sabido, del maíz surgen una serie de comidas que permitieron alimentar a los pueblos que los cultivaron. Por ejemplo, las "tortillas rellenas" de la prehispanidad estaban "diseñadas" para emplearse como alimento de viaje. Un uso similar al de las actuales pupusas. La primera descripción de las tortillas rellenas es de los primeros años de la conquista española, en el siglo XVI; pero no se refiere a ningún nombre en particular. La preparación de tortillas de maíz rellenas, usualmente de frijoles, hierbas y quizás carne, estaba extendida por la región centroamericana a la llegada de los españoles. No se desconoce con certeza el origen de la palabra Pupusa.

Otros derivados del maíz en aquellos tiempos eran el atole y el chilate, que formaron parte de la gastronomía de los indígenas pipiles, pero sufrieron cambios con la llegada de los españoles y sus diferentes productos alimenticios. Por ejemplo, la receta actual de atol de elote incorpora ingredientes que no eran autóctonos, como la leche y el azúcar. La introducción de la planta de plátano tuvo impacto en la elaboración del tamal y sus ingredientes. En fin, hay mucho de qué hablar sobre la transformación de la gastronomía pipil por la llegada de los españoles.

En el caso de otros países, por ejemplo, Cuba, se sabe que, cuando Cristóbal Colón llegó al Nuevo Mundo (1492), sus hombres encontraron en la isla grandes 


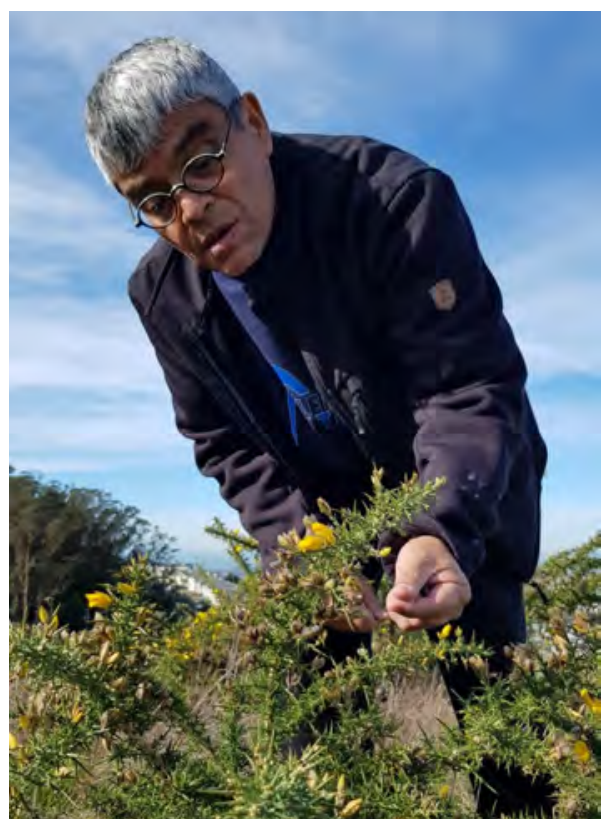

Dr. Ramón D. Rivas

campos con un extraño cereal, hasta entonces desconocido en el Viejo Mundo. Se trataba del maíz, al cual los "aborígenes" de esta isla lo llamaban mais o mahis, y que lo consumían asado, salcochado, fresco, seco y hecho harina. Todo ello nos lleva a pensar que este cereal es propio de nuestras tierras, pero que no se sabe a ciencia cierta quién inició con su cultivo y apropiación gastronómica.

El Inca Garcilaso de la Vega escribió referente a la alimentación de los indígenas mexicanos y peruanos. El texto De la Vega, tomado del libro titulado Maíz: Regalo de los dioses, de Echeverría y Muñoz (1988), dice de la siguiente manera:

...el grano que los mejicanos y los barloventanos llaman maíz y los del Perú, zara, porque es el pan que ellos tenían es de dos maneras: el uno es duro que llaman muruchu y el otro tierno y de mucho regalo que llaman capia, cómenlo en lugar de pan, tostado, o cocido en agua simple;... para sus sacrificios solemnes, como ya se ha dicho, hacían pan de maíz, que llaman zancu, y para su comer, no de ordinario, sino de cuando en cuando por vía de regalo, hacían el pan que llaman humita... También hacen las gachas que llaman api. De la harina y el agua simple hacían el brebaje que beben y del brebaje acedándole, como los indios lo saben hacer, se hace muy lindo vinagre; de las cañas antes que madure el grano, se hace muy linda miel porque las cañas son dulces... Las cañas 
secas y sus hojas son de mucho mantenimiento y muy agradables para las bestias...

En la actualidad, — si ustedes recuerdan—, el maíz sigue siendo el alimento de todos los pueblos americanos, pero también es considerado como el sustituto del petróleo, algo que generó mucha controversia en los años 2000. Se propuso para hacer el biodiésel, el cual se extraería del tallo y las hojas de las plantas de maíz a fin de convertirlos en diésel y combustible para aviones.

Muchos sectores del mundo se pronunciaron en contra de esta política, ya que consideraron que la semilla sagrada se estaría sembrando para estar al servicio del capital. ¿Cuáles serían las consecuencias? Asturias (1949), lo dice en su libro Hombres de Maíz, que se inspira en un mito del Popol Vuh, uno de los libros sagrados de los mayas: "sembrado para comer es sagrado sustento del hombre que fue hecho de maíz. Sembrado para negocio es el hambre del hombre que fue hecho de maíz". En este importante libro, se hace la incisiva denuncia de los devastadores efectos que el capitalismo y las grandes empresas internacionales tuvieron en las costumbres, creencias ancestrales, identidad y la seguridad de los campesinos guatemaltecos.

\section{El maíz como fuente de cultura}

Del maíz se han escritos múltiples historias, desde cuentos, leyendas y poesía hasta otros tipos de géneros literarios. Esto se ha realizado desde los tiempos ancestrales, cuando los pipiles, por ejemplo, realizaron hasta cantos por el cultivo del maíz.

El antropólogo, Schultze Jena (1982), hace referencia, en su libro "Mitos y Leyendas de los pipiles de Izalco", a que "el maíz y la lluvia están unidos a la religión y a los mitos de campesino indígena. El dios del maíz nace en el lugar de la lluvia y de la niebla”. Estas palabras vertidas en uno de los cantares más antiguos recogidos por el Sahagün...El texto VI relata cómo los Muchachos de la Lluvia sacan el maíz de las entrañas de la montaña, y con disfraz de mito describe, a la vez, el paso de la cacería a la agricultura. Originalmente, los Muchachos de la Lluvia eran puramente carnívoros. Como cazadores y moradores selváticos vivían en completa armonía, cuando aparece un gigante perturbador de la paz y del orden".

Esta figura tiene su origen en una de las primeras leyendas mexicanas, que habla de una antigua raza gigante, la que también, — se dice-, puede tener otro origen. 
Rivas, Ramón D. El maíz, fuente de cultura mesoamericana. Págs. 44-53.

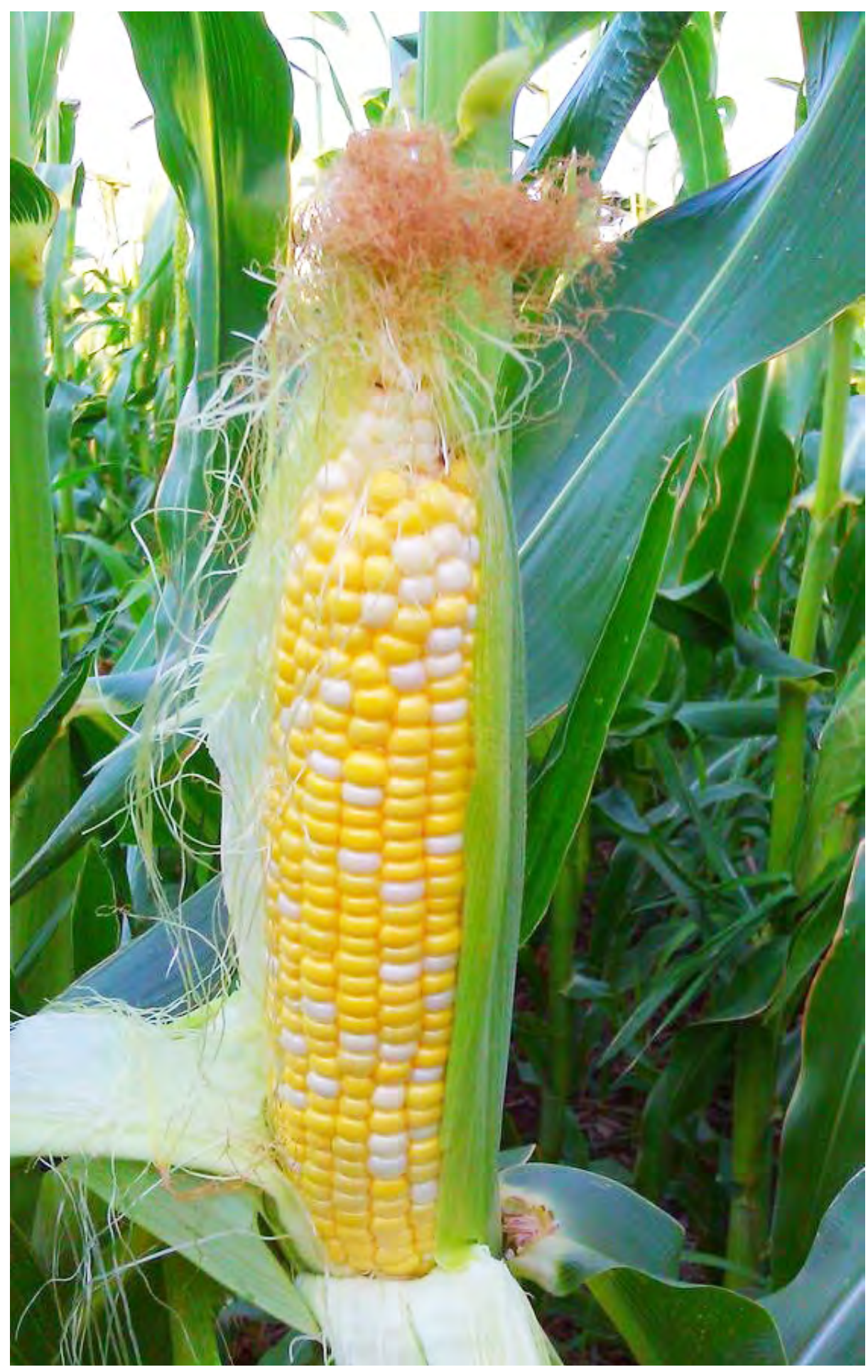


Un ejemplo actual de poesía para el maíz es la siguiente estrofa de Pablo Neruda:

\section{Oda al Maíz}

América, de un grano
de maíz te elevaste
hasta llenar
de tierras espaciosas
el espumoso
océano.

Fue un grano de maíz tu geografia.

$$
\text { El grano }
$$

adelantó una lanza verde,

la lanza verde se cubrió de oro

y engalanó la altura

del Perú con su pámpano amarillo.

También existe una fuerte relación del maíz con la religión de los ancestros. Para los mayas y pipiles, el cultivo del maíz era sagrado, por lo que era incorporados en sus ritos y celebraciones agrícolas. Por ejemplo, en el Perú, las celebraciones del Inti Raymi (o fiestas del solsticio de junio) se inician con la cosecha del maíz y de otros cultivos. En esta ocasión, los miembros de la comunidad comparten chicha, tamales y otras preparaciones hechas en base a maíz.

Según datos tomados del libro Hijos del Maíz, en la región mesoamericana hay muchas fiestas ancestrales que tienen como base el cultivo del maíz. Textualmente, el documento dice así:

El calendario agrofestivo de Mesoamérica está colmado de celebraciones ligadas al maíz, como es la fiesta de La Candelaria o bendición de las semillas ( 2 de febrero), el día de Santa Cruz (finales de abril e inicios de mayo) para la petición de la lluvia y San Isidro Labrador para la bendición de los animales. El 1 y 2 de noviembre es la celebración de los muertos en la cual se toma una bebida ceremonial llamada colada morada o mazorca. Todas estas festividades están relacionadas con el ciclo del maíz en un sincretismo entre la religión cristiana y la cosmovisión mesoamericana... Las comunidades trashumantes Rarámuri que habitan en la Sierra Madre Occidental al Norte de México, organizan su existencia en torno al maíz (sunú)...”Para los Mexica, la planta del maíz fue un don de los dioses. El propio Quetzalcóatl, después de la creación del Quinto Sol, se encargó de buscarlo para entregarlo a los humanos; por esta razón el maíz tenía un carácter divino. 
Analicemos el siguiente relato indígena precolombino recogido por Galeano (1994) en Memoria del Fuego.

Los dioses hicieron de barro a los primeros mayas-quichés. Poco duraron. Eran blandos, sin fuerza; se desmoronaron antes de caminar.

Luego probaron con la madera. Los muñecos de palo hablaron y anduvieron, pero eran secos: no tenían sangre ni sustancia, memoria ni rumbo. No sabían hablar con los dioses, o no encontraban nada que decirles.

Entonces los dioses hicieron de maíz a las madres y a los padres. Con maíz amarillo y maíz blanco amasaron su carne. Las mujeres y los hombres de maíz veían tanto como los dioses. Su mirada se extendía sobre el mundo entero.

Los dioses echaron un vaho y les dejaron los ojos nublados para siempre, porque no querían que las personas vieran más allá del horizonte. ${ }^{6}$

Esto nos puede llevar a interpretar que ha sido la zona mesoamericana donde el maíz tuvo su aparición y su proceso de adaptación. Desde este lugar ha emigrado a otros países o regiones del mundo, por lo menos, así es interpretado por muchos investigadores.

En la era moderna, en los pueblos mestizos de habla hispana, generalmente, se recuerdan los antiguos ritos de la cosecha solo entre la generación mayor. Antes de la siembra, se recomienda el grano del maíz en rezos al amparo de Dios, de la Virgen o de San Isidro, el patrón de los labradores, quien protege la joven simiente. Una de las oraciones españolas que aún se reza en El Salvador es la siguiente: "San Isidro Labrador, quita el agua y pon el sol" cuando los inviernos son calamitosos, y "San Isidro Labrador, pon el agua y quita el sol”, cuando hay sequía.

Pasando al ámbito político, hay acontecimientos importantes que debemos analizar. Uno de ellos es en lo político-cultural, el cual ocurrió en Guatemala, donde los diputados lo analizaron y consideraron que el maíz tenía que ser declarado bien cultural, en la categoría de patrimonio natural y cultural a través de un decreto hecho el 22 de septiembre de 2011, por ser un elemento fundamental para la alimentación y la espiritualidad del pueblo maya. El Decreto dice así: "El maíz, todas sus variedades, tipos autóctonos, propios, distintivos, originarios o peculiares de los suelos y climas de Guatemala es desde hoy Patrimonio Cultural de la Nación". 


\section{El maíz como fuente de intercambio comercial}

No solo el cacao ha servido como fuente de intercambio o moneda. Por ejemplo, en Perú se conoce que los indígenas utilizaron el maíz como moneda. Un estudio hecho por Soler Bustamante (1954), señala que "durante la cosecha se presentan compradores o negociantes de diferentes lugares y adquieren el maíz con moneda o en base a trueques con cameros, lana, tejidos... En época de choclos es común el cambalache con papas, ocas y ollucos". En esta investigación se encontró que un saco de maíz equivale a otro saco igual de papas.

\section{Aztecas y mayas unidas por el maíz}

Los aztecas y mayas cultivaron la tierra con énfasis en el maíz. Según historiadores, la vida de los aztecas y los mayas giró alrededor de la milpa, pues ninguna otra civilización dependió tanto del maíz como esta. Desde esos tiempos, el mes de abril el tiempo para empezar a prepararse para la siembra. Si las lluvias tardaban, entonces los aztecas hacían sacrificios a su dios Tlaloc. Ellos no creían necesario construir un sistema de irrigación, por lo que dependieron totalmente de las lluvias para cultivar la tierra.

Los pipiles consideraban que existen cuatro columnas que sostienen la filosofía indígena sobre las cosas que los rodeaban: la fruta del campo, que se convertía en su carne y sangre; la tierra, de la cual extraen la fruta; el agua, sin la que nada puede crecer; y los astros, que son los que imperan sobre todas las cosas.

\section{A manera de conclusión}

Creo que hablar del maíz es un tema que da para muchas ponencias; horas y horas de análisis podrían resultar de este tema. He querido solo resaltar lo más importante desde el punto de vista antropológico. Podemos hacerlo desde la historia, la religión o cualquier otra rama de la ciencia.

Pero lo importante, en toda esta exposición, es señalar que, por años, las migraciones han permitido la propagación de la cultura, $\mathrm{y}$, por ende, alimentos o cultivos como el maíz. Además, este tipo de cultivo es tan identitario, que permite que cada región o pueblo los incluyan como parte de su existencia misma, hasta el punto de construir una cosmovisión según sus creencias religiosas.

Las poblaciones indígenas del Nuevo Mundo, especialmente mayas, aztecas, chibchas y quechuas, cultivaban el maíz en forma intensiva, principalmente en los valles. Por las evidencias rescatadas, este producto constituyó la fuerza dinámica de su desarrollo. Asimismo, desde el génesis de su cultivo, el maíz ha 
sido utilizado para la preparación de las tortillas, trabajo que a través de miles de años se ha mantenido casi inalterable. Finalmente, con el maíz creamos cultura, identidad y, por qué no decirlo, creamos una relación muy propia en la región, tanto que nuestra cultura es conocida como del maíz.

\section{Algunas curiosidades sobre el maíz}

Elutamal sería 'tamal de elote', y tamal, la denominación náhuat para 'tortilla'.

Mil también se refiere 'terreno sembrado'en náhuat. Así, tunalmil era la cosecha de sol, y xupanmil, la de invierno, y apanmil, la de riego o de apante.

Campesinos salvadoreños aún usan estas denominaciones.

Para poder cultivar el maíz, se requiere de la intervención de la mano del ser humano, ya que el grano no se puede desprender por sí mismo.

En América, existen aproximadamente 300 razas de maíz (Pearsall, 1986).

\section{Referentes bibliográficos}

Asturias, M. A. (1949). Hombres de maiz. Argentina, Argentina: Losada.

Chinchilla Aguilar, E. (1974). Los jades y las cementeras. Guatemala, Guatemala: José de Pineda Ibarra.

Echeverría, J. y Muñoz, C. (1988). Maiz: Regalo de los dioses. Otavalo, Ecuador: Instituto Otovaleño de Antropología.

Galeano, E. (1994). Memoria del fuego. España, España: Siglo XXI

Mundorojas. (20 de noviembre del 2009). La historia del maíz en El Salvador [Entrada en el blog]. Recuperado de http://lahistoriadelmaizenelsal vador.blogspot.com

Schultze Jena, L. (1982). Mitos en la lengua materna en los Pipiles de Izalco en El Salvador. San Salvador, El Salvador: Cáceres.

Soler Bustamante, E. (1954). Proyecto Yauyos-Huarochiri: La agricultura en la comunidad de San Pedro de Huancaire. Revista del Museo Nacional, (23), 90-139. 


\section{Pieza de Exposición}

Museo Universitario de Antropología
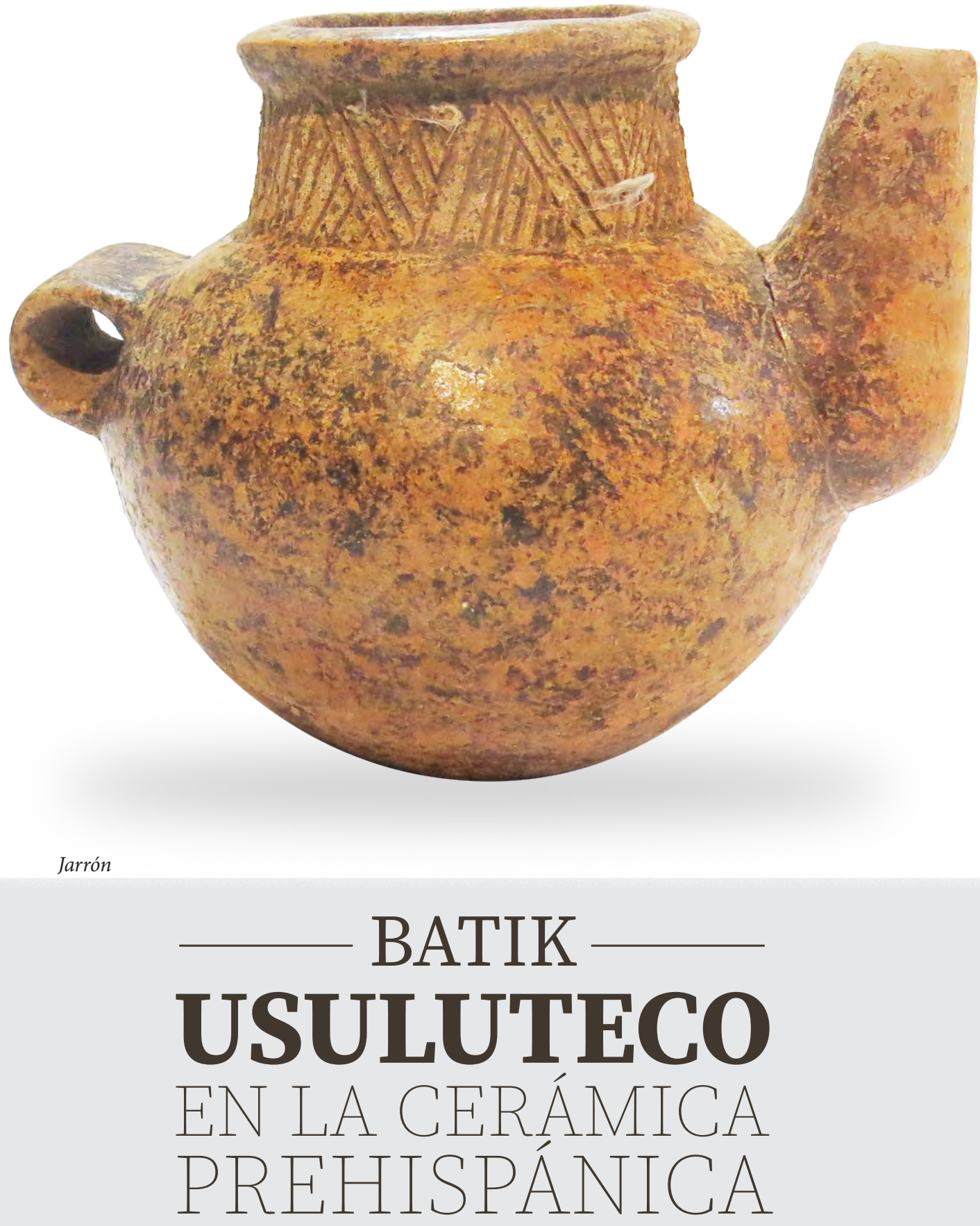